Article

\title{
Fabrication of Cellulose Nanocrystal/Silver/Alginate Bionanocomposite Films with Enhanced Mechanical and Barrier Properties for Food Packaging Application
}

\author{
Mithilesh Yadav ${ }^{1, *(D)}$, Yu-Kuo Liu ${ }^{1}$ and Fang-Chyou Chiu ${ }^{1,2, *}$ \\ 1 Department of Chemical and Materials Engineering, Chang Gung University, Taoyuan 333, Taiwan; \\ ykliu@mail.cgu.edu.tw \\ 2 Department of General Dentistry, Chang Gung Memorial Hospital, Taoyuan 333, Taiwan \\ * Correspondence: maxson@mail.cgu.edu.tw (F.-C.C.); dryadavin@gmail.com (M.Y.); \\ Tel.: +88-69-5367-8628 (F.-C.C.); +88-69-0547-3797 (M.Y.)
}

Received: 11 October 2019; Accepted: 22 October 2019; Published: 25 October 2019

\begin{abstract}
Eco-friendly cellulose nanocrystal/silver/alginate (CNC/Ag/Alg) bionanocomposite films were successfully prepared by blending of $\mathrm{CNC}$ with $\mathrm{Ag} / \mathrm{Alg}$ solution. The $\mathrm{CNC}$ was fabricated from cellulose microcrystal (CMC) by acid hydrolysis method. The Ag nanoparticles (AgNPs) were generated by using $\mathrm{Alg}$ as a reducing agent through hydrothermal process. AgNPs-included composite films showed characteristic plasmonic effect of the AgNPs with the maximum absorption at $491 \mathrm{~nm}$ and they also showed high ultraviolet (UV) barrier properties. The CNC/Ag/Alg composite films were analyzed by using scanning electron microscopy, transmission electron microscopy, optical microscopy, Fourier transform infrared spectroscopy, and X-ray diffraction technique. Depending on the type of nanofillers, tensile strength of the composite films increased by $39-57 \%$ and water vapor permeation decreased by $17-36 \%$ compared with those of the neat Alg films. The Ag/Alg and $\mathrm{CNC} / \mathrm{Ag} / \mathrm{Alg}$ films showed brown color as detected from the increase of both ' $\mathrm{b}$ ' and ' $a$ ' parameters by colorimeter. The UV and water barrier properties of Alg based composite films were found higher than the Alg films. The obtained results suggested that the prepared composite films can be used in food packaging applications.
\end{abstract}

Keywords: cellulose nanocrystal; alginate; bionanocomposite films; mechanical property

\section{Introduction}

Plastic packaging films including poly(vinyl chloride), polyethylene, and polypropylene are widely utilized in the market owing to many advantages, such as low price, light weight, good mechanical performance, and water resistance. However, such films cause waste disposal problems in environment due to its non-biodegradable nature [1]. So, today, some of these conventional plastic films are replaced by sustainable-based materials [2,3]. The natural polysaccharides, such as chitosan, alginate (Alg), and carrageenan, etc., are characterized as sustainable materials due to their biodegradability and non-toxicity nature in environment. The films made of such polysaccharides have been studied by researchers for packaging purpose due to their processability and availability [4]. Alg is derived from brown seaweed [5] and consists of a linear block co-polymer of 1,4-linked $\beta$-d-mannuronic and $\alpha$-l-guluronic residues in varying proportions. It is commonly used in food and biotechnology industries because of its biocompatible, low-cost, abundantly available, and environmentally friendly nature. Alg also has great potential in various applications [6,7], which include film forming, gel producing, and emulsion stabilizing features [8,9]. The free standing film of Alg showed poor mechanical and water barrier properties resulted from its hydrophilic feature, thereby limiting the 
versatility of Alg. Alg was, hence, reinforced by various nanofillers [10] for preparing nanocomposites to overcome its drawbacks in film applications. Silver (Ag) frequently served as a nanofiller in food packaging materials owing to its antibacterial characteristics. Numerous methods were used to synthesize Ag nanoparticles (AgNPs) [11,12], but only few researchers [13-15] applied Alg in fabricating AgNPs. The AgNPs were fabricated by Liu et al. [16], who used Alg as a stabilizer under gamma radiation. Narayanan et al. [17] studied the food packaging nature of $\mathrm{Ag} / \mathrm{Alg}$ nanocomposite films. Tankhiwale et al. [18] and Yoksan et al. [19] reported the successful incorporation of AgNPs in food packaging films as an antimicrobial agent. The food packaging nature of Alg films with others fillers incorporation was also studied by other researchers [20-22].

Cellulose is the most abundant natural biopolymer on earth, occurring in wood and cell wall of plants $[23,24]$. It is composed of $\beta-1,4$-linked glucopyranose units that forms a high molecular weight linear homopolymer [25]. Cellulose has many useful applications after its modifications. The chemical and mechanical degradations of cellulose lead to a product of low molecular weight or cellulose microcrystal (CMC). CMC is well-known in applications of food, cosmetic, and medical industries [26]. Cellulose nanocrystal (CNC) can be extracted from plant or it can be extracted from $\mathrm{CMC}$ by acid hydrolysis process $[27,28]$. CNC is an emerging biopolymer with the advantages of abundance, renewability, biodegradability, high mechanical properties, high reinforcing ability, and low density [29]. The geometric dimensions of needle shaped CNC depend on the initial source of cellulose, which accounts for widths of 5-20 nm and lengths of $100 \mathrm{~nm}-2 \mu \mathrm{m}$. The CNC has been reported, playing as nanofiller, to increase the mechanical, and water barrier properties of Alg films for packaging application [30,31]. Dong et al. [32] used CNC/Ag to improve the tensile and antimicrobial properties of chitosan. Yang et al. [33] fabricated AgNPs-bacterial cellulose (BC)/Alg composite by immersing $\mathrm{BC} / \mathrm{Alg}$ template into $\mathrm{AgNO}_{3}$ solution. This composite showed improvement in mechanical, antibacterial, and water swelling ability of pure BC. To the best of our knowledge, the synergistic effects of incorporating $\mathrm{CNC}$ and $\mathrm{Ag}$ on the mechanical and barrier (water and ultraviolet (UV)) properties of Alg composite film has not been yet reported.

The aim of this study was to fabricate $\mathrm{Ag} / \mathrm{Alg}$ composite nanoparticles through chemical reduction of $\mathrm{Ag}^{+}$by applying a "green" approach through hydrothermal method of using Alg itself as reductant. Afterwards, the biosynthesized Ag/Alg composite nanoparticles were mixed with $\mathrm{CNC}$ to fabricate $\mathrm{CNC} / \mathrm{Ag} / \mathrm{Alg}$ composite films using solution mixing then followed by casting technique. Further, the morphology, interactions among the components, and properties, such as color, mechanical, and barrier (water and $\mathrm{UV}$ ) of the $\mathrm{CNC} / \mathrm{Ag} / \mathrm{Alg}$ bionanocomposite films were characterized by various techniques.

\section{Materials and Methods}

\subsection{Chemical and Reagents}

Silver nitrate and sodium alginate were obtained from Sigma-Aldrich (Taipei, Taiwan). Sulfuric acid was purchased from J.T. Baker, Taiwan. CMC (Arbocel ${ }^{\circledR}$ UFC100) was received from (J. RETTENMAIER \& SOHNE, Saint-Germain-en-Laye, France). Jardino universal potting soil (garden soil) was used for degradation test of fabricated films. Phosphotungstic acid, as staining agent, was received from Sigma-Aldrich. The deionized/millipore water was used in the whole research.

\subsection{Fabrication of $C N C, C N C / A l g, A g / A l g$, and $C N C / A g / A l g$ Samples}

The CNC was fabricated from CMC using sulfuric acid hydrolysis method. The details for CNC fabrication was reported in recently published paper [34]. The obtained CNC was measured with length of $100-500 \mathrm{~nm}$ and diameter of $5-30 \mathrm{~nm}$.

The Alg solution was fabricated by dissolving Alg $(0.95 \mathrm{~g})$ in $80 \mathrm{~mL}$ deionized water with magnetic stirring for $1 \mathrm{~h}$. Water dispersed CNC (by ultrasonication) was charged into the Alg solution to achieve $\mathrm{CNC} / \mathrm{Alg}$ solution under stirring for $1 \mathrm{~h}$ at $27^{\circ} \mathrm{C}$. Afterwards, the CNC/Alg solution was spread on petri dish for film forming. The resulting films were treated with air drying process at $40{ }^{\circ} \mathrm{C}$ for $24 \mathrm{~h}$ to 
remove water. The neat Alg film was prepared according to the above mentioned procedure, except without $\mathrm{CNC}$ addition.

The Ag/Alg solution was fabricated by mixing of $100 \mu \mathrm{L}$ of $1 \mathrm{M} \mathrm{AgNO}_{3}$ solution and the above Alg solution (1 wt.\%). The solution was further put in an oven at $60^{\circ} \mathrm{C}$ for $12 \mathrm{~h}$ without any stirring. Next, the obtained brown solution of Ag/Alg was kept for magnetic stirring for $12 \mathrm{~h}$. By a similar casting method to the $\mathrm{CNC} / \mathrm{Alg}$ film preparation, the $\mathrm{Ag} / \mathrm{Alg}$ composite film was prepared.

The $\mathrm{Ag} / \mathrm{Alg}$ solution was mixed with $\mathrm{CNC}$ solution under stirring for $2 \mathrm{~h}$. The resulting solution was casted on a petri dish to prepare $\mathrm{CNC} / \mathrm{Ag} / \mathrm{Alg}$ composite films. The details about the procedure for fabricating the $\mathrm{Alg}$, $\mathrm{CNC} / \mathrm{Alg}, \mathrm{Ag} / \mathrm{Alg}$, and $\mathrm{CNC} / \mathrm{Ag} / \mathrm{Alg}$ solutions and films are shown in Figure 1. The thickness of all the prepared films was measured with a dial thickness micrometer (SM-112, Dole Teclock, Tongyuan, Japan).

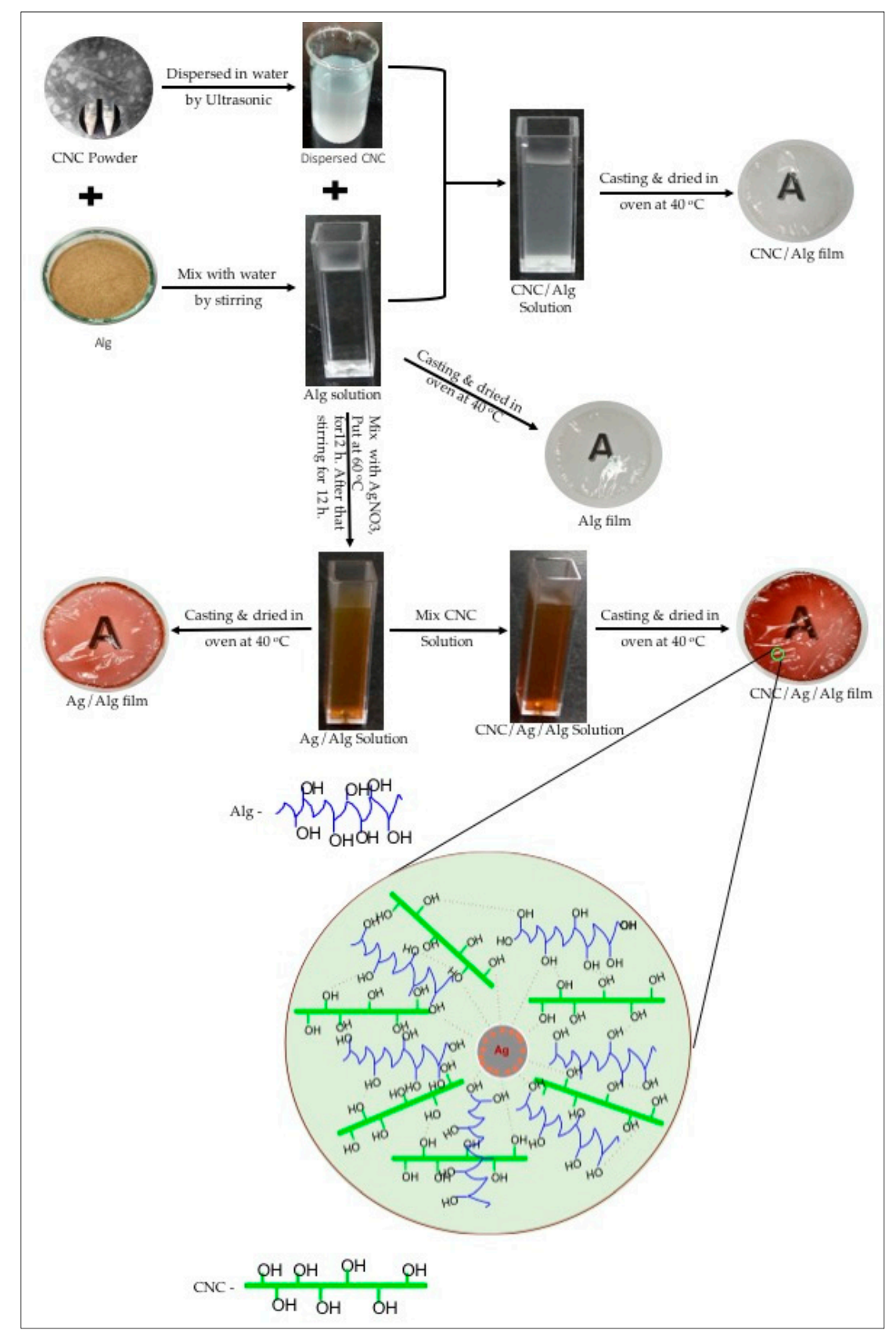

Figure 1. Schematic representation of fabricated solutions and films of alginate (Alg), cellulose nanocrystal (CNC)/Alg, silver (Ag)/Alg, and CNC/Ag/Alg. 


\subsection{Fourier-Transform Infrared Spectroscopy (FTIR)}

The interactions among the components in fabricated composite films were analyzed with FTIR (400-4000 $\mathrm{cm}^{-1}$ ) using Bruker Tensor 27 IR spectrometer (Karlsruhe, Germany).

\subsection{Field Emission Scanning Electron Microscopy (FESEM)}

FESEM (Jeol JSM-7500F, Akishima, Tokyo, Japan) was used for observing the surface and cross-sectional morphology of the prepared composite samples. The Energy-dispersive X-ray spectroscopy(EDS) analysis was carried out to confirm the presence of AgNPs in composite films.

\subsection{Transmission Electron Microscopy (TEM)}

Carbon film covered copper grids (5-6 nm film thickness, 200 mesh, EMS FF200) were used for imaging CNC samples. One drop of the CNC suspension $(0.1 \mathrm{mg} / \mathrm{mL})$ was placed on a grid for $30 \mathrm{~min}$ and wicked away with a filter paper. Further, the sample was stained by depositing a drop of (2 wt.\%) phosphotungstic acid (PTA) solution on the grid for 20 min and wicking the excess solution away with a wet filter paper. The grid was put into oven at $70{ }^{\circ} \mathrm{C}$ for drying before insertion into the microscope. Finally, the CNCs were analyzed by a JEOL (JEM-1230 electron microscope, Tokyo, Japan) operated at an accelerating voltage of $200 \mathrm{kV}$.

\subsection{Optical Microscopy (OM)}

Morphology and dispersion of CNC within (or without) Alg film were examined by OM (Olympus BX-50, Tokyo, Japan).

\subsection{X-ray Diffraction (XRD)}

XRD patterns of all samples were recorded with X-ray diffractometer (D2, Bruker, Karlsruhe, Germany). The crystallinity of CMC and CNC samples was calculated using Equation (1):

$$
\mathrm{CI}(\%)=\frac{\mathrm{I}_{002}-\mathrm{I}_{\mathrm{am}}}{\mathrm{I}_{002}} \times 100,
$$

where $\mathrm{I}_{002}$ is the intensity of the crystalline region of cellulose $\left(2 \theta=22.5^{\circ}\right)$, and $\mathrm{I}_{\mathrm{am}}$ is the intensity of the amorphous region $\left(2 \theta=16.3^{\circ}\right)$.

\subsection{Thermalgravimetric Analysis (TGA)}

The degradation behavior and thermal stability of prepared samples were studied in nitrogen atmosphere by operating a thermogravimetric analyzer (TA Q50, TA instrument, New Castle, DE, USA). The samples were heated from $40{ }^{\circ} \mathrm{C}$ to $700{ }^{\circ} \mathrm{C}$ at a rate of $10^{\circ} \mathrm{C} \mathrm{min}-1$.

\subsection{Opacity and UV Visibility}

The opacity of prepared films was defined by the following Equation (2) using a UV spectrophotometer (Jasco V-650, Tokyo, Japan) for the measurement:

$$
\text { Opacity }=\frac{\mathrm{Abs}_{600}}{\mathrm{~d}}
$$

where $\operatorname{Abs}_{600}$ is the absorbance at $600 \mathrm{~nm}$, and $\mathrm{d}$ is the film thickness $(\mathrm{mm})$. The transparency of the films was determined following the light transmittance in the light wavelength region (ranged from $190 \mathrm{~nm}$ to $900 \mathrm{~nm}$ ). The used scan rate was $1000 \mathrm{~nm} / \mathrm{min}$, and three replicates of each material were measured. 


\subsection{Film Water Solubility (FWS)}

The procedure detail of FWS was followed by Yadav et al. [34]. The following, Equation (3), was used to measure FWS of the prepared films.

$$
\mathrm{FWS}=\frac{\mathrm{W}_{\mathrm{i}}-\mathrm{W}_{\mathrm{f}}}{\mathrm{W}_{\mathrm{i}}} \times 100,
$$

where $W_{i}$ and $W_{f}$ represent initial and final dry weight of film.

\subsection{Moisture Absorption}

ASTM D5229 [35] was followed for calculating the moisture absorption of Alg, CNC/Alg, Ag/Alg, and $\mathrm{CNC} / \mathrm{Ag} / \mathrm{Alg}$ films of size $1 \times 1 \mathrm{~cm}^{2}$ dried at $105^{\circ} \mathrm{C}$ for $24 \mathrm{~h}$. The dried films were conditioned in a humid chamber (Giant Force, Xinbei, Taiwan) at $25^{\circ} \mathrm{C}$ to attain $95 \%$ relative humidity. After a certain time, the films were removed from the chamber and weighed. The following formula [30] was used to determine the moisture absorption (MA).

$$
\mathrm{MA}(\%)=\frac{\mathrm{W}_{\mathrm{t}}-\mathrm{W}_{\mathrm{i}}}{\mathrm{W}_{\mathrm{i}}} \times 100,
$$

where $\mathrm{W}_{\mathrm{t}}$ and $\mathrm{W}_{\mathrm{i}}$ represent the film weight at time $\mathrm{t}$ and before exposure to $95 \% \mathrm{RH}$, respectively.

\subsection{Water Vapor Permeation (WVP)}

According to ASTM-E96/E96-05, the WVP of prepared films was studied. The details of the procedure was described previously [34]. In each test petri dish, $20 \mathrm{~mL}$ of distilled water was added, leaving a distance of approximately $1 \mathrm{~cm}$ between the water surface and the film. The film samples were sealed to the dish mouth by a water-resistant sealant. The petri dishes were conditioned in a humid chamber (Giant Force, Taiwan) at $27^{\circ} \mathrm{C}$ to ensure $75 \% \mathrm{RH}$, and weight was measured at a certain interval of time. Equation (5) was used to calculate the WVP values.

$$
\operatorname{WVP}\left(\mathrm{g} \mathrm{m}^{-1} \mathrm{~s}^{-1} \mathrm{~Pa}^{-1}\right)=(\mathrm{w} / \mathrm{t}) \cdot \gamma \cdot(\mathrm{A})^{-1}(\Delta \mathrm{p})^{-1},
$$

where $\mathrm{w}$ is the weight loss of the petri dishes $(\mathrm{g}), \gamma$ is the film thickness $(\mathrm{m}), \mathrm{A}$ is the cross-section area of the film $\left(\mathrm{m}^{2}\right), \mathrm{t}$ is the time (s), and $\Delta \mathrm{p}$ is the vapor pressure difference.

\subsection{Color}

The color properties of the films were measured by using a TES-135A colorimeter (Taiwan). The obtained parameters are the lightness (L) and chromatic parameters: a (green $(-a)$ to red $(+a)$ ) and $b$ (blue $(-b)$ to yellow $(+b)$ ) colors. Based on the measured parameters, the total color difference $(\Delta \mathrm{E})$ was calculated using Equation (6):

$$
\Delta \mathrm{E}=\sqrt{\left(\mathrm{L}^{*}-\mathrm{L}\right)^{2}+\left(\mathrm{a}^{*}-\mathrm{a}\right)^{2}+\left(\mathrm{b}^{*}-\mathrm{b}\right)^{2}},
$$

where $L^{*}=95.90, a^{*}=-1.16$, and $b^{*}=+1.56$ are the values of standard white plate. $L, a$, and $b$ are the measured values of the prepared films. 


\subsection{Tensile Properties}

The tensile properties of film specimens $(10 \mathrm{~mm} \times 60 \mathrm{~mm} \times 0.01 \mathrm{~mm}$ ) were determined (according to ASTM D638) using a Gotech AI-3000 system (Taichung, Taiwan). A crosshead speed of $10 \mathrm{~mm} / \mathrm{min}$ and, initial grip distance of $40 \mathrm{~mm}$ were used for the tests. The pull tests of the films in terms of tensile strength and elongation at break (\%) was calculated by following formula:

$$
\begin{gathered}
\text { Tensile strength }\left(\frac{\mathrm{N}}{\mathrm{mm}^{2}}\right)=\frac{\text { Breaking force }(\mathrm{N})}{\text { Cross sec tional area of the sample }\left(\mathrm{mm}^{2}\right)} \times 100, \\
\text { Elongation at break }(\%)=\frac{\text { The increase in length at breaking point }(\mathrm{mm})}{\text { Original length }(\mathrm{mm})} \times 100 .
\end{gathered}
$$

\subsection{Biodegradability}

Soil burial tests for biodegradation of the films were conducted by a method described by Martucci et al. [36]. The films were cut into rectangular pieces $(2 \mathrm{~cm} \times 2 \mathrm{~cm})$, dried in an oven at $105^{\circ} \mathrm{C}$ for $6 \mathrm{~h}$, and weighed $\left(\mathrm{W}_{\mathrm{i}}\right)$. A total of $35 \mathrm{~g}$ of soil was poured into a plastic pot up to a thickness of approximately $1 \mathrm{~cm}$. Then, the films were buried under soil at a depth of $0.5 \mathrm{~cm}$ from the soil surface. The assay was completed at $25^{\circ} \mathrm{C}$ and (30\%) RH by using a humid chamber (Giant Force, Taiwan). Films were taken from the soil at different times and cleaned carefully with tissue paper. Consequently, the films were dried in an oven at $105^{\circ} \mathrm{C}$ for $6 \mathrm{~h}$ and weighed $\left(\mathrm{W}_{\mathrm{t}}\right)$ to determine the percentage of weight loss using the following equation:

$$
\text { Weight loss }(\%)=\frac{W_{i}-W_{t}}{W_{i}} \times 100 .
$$

\section{Results}

\subsection{Fourier-Transform Infrared Spectroscopy}

FTIR spectra of CMC, CNC, Alg, Ag/Alg, CNC/Alg, and CNC/Ag/Alg samples are shown in Figure 2a,b. The existence of two new peaks at 1646 and $1241 \mathrm{~cm}^{-1}$ in CNC spectrum confirmed that CMC was acidified. In the Alg spectrum, the characteristic peaks at 1606 (asymmetric stretching vibrations of carboxylate anions), 1414 (symmetric stretching vibrations of carboxylate anions), and $3409 \mathrm{~cm}^{-1}$ (O-H stretching vibration) [37] were assigned. When $\mathrm{AgNO}_{3}$ was added to $\mathrm{Alg}$, the peaks at 1606-1597 and 1414-1384 sharpened, thereby suggesting that AgNPs were generated by the reduction of $\mathrm{Ag}^{+}$with $\mathrm{Alg}$ [13]. The shifting of peak from $3409 \mathrm{~cm}^{-1}$ (in $\mathrm{Alg}$ ) to $3426 \mathrm{~cm}^{-1}$ (in Ag/Alg film) suggests a certain degree of interaction occurred between $\mathrm{Ag}$ and $\mathrm{O}$. The functional groups (-OH and $-\mathrm{COOH}$ ) of Alg should be involved for fabricating AgNPs [38]. After CNC was added to Alg, the peaks at 3409-3404 (O-H stretching vibration), 1606-1602, and 1413-1410 $\mathrm{cm}^{-1}$ sharpened, thereby proving the miscibility (due to presence of hydrogen bonding) [39] between $\mathrm{CNC}$ and Alg. When CNC was added to Ag/Alg, the peaks at 3426-3430 (O-H stretching vibration) and 1597-1605 and $1384-1413 \mathrm{~cm}^{-1}$ sharpened, confirming again that hydrogen bonding type interaction occurred between $\mathrm{Ag} / \mathrm{Alg}$ and $\mathrm{CNC}$. 

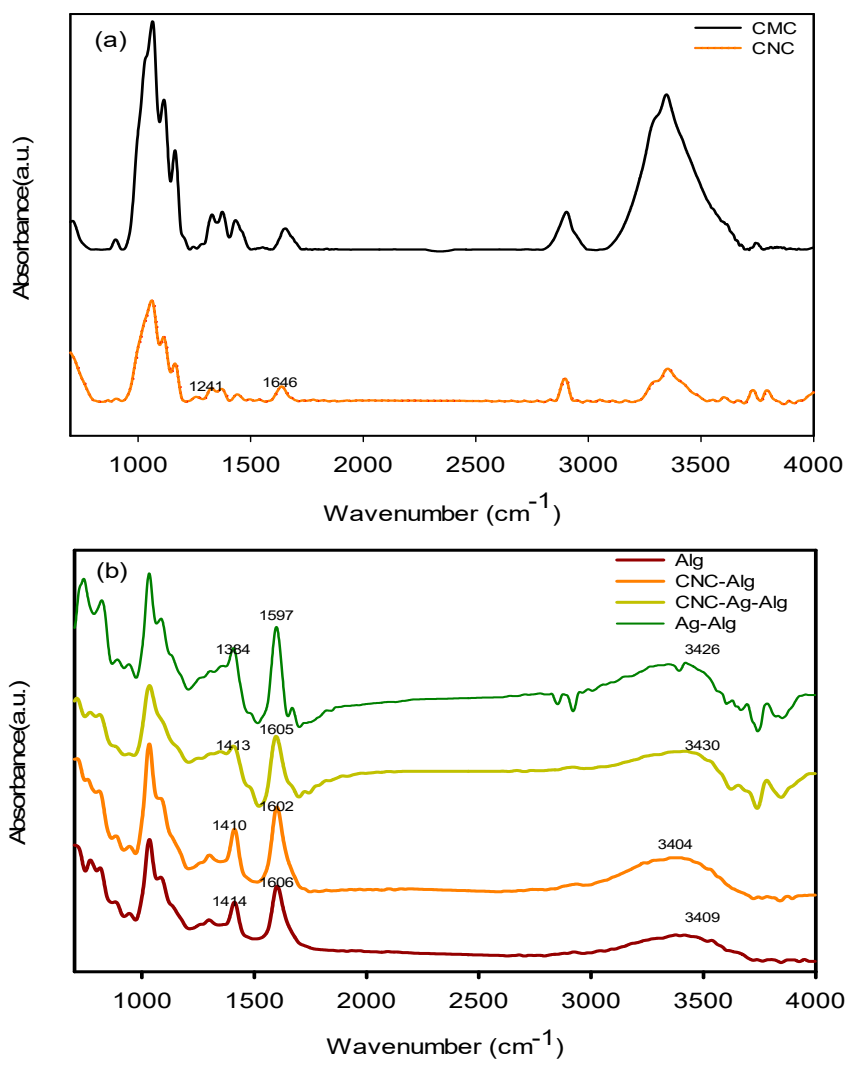

Figure 2. FTIR spectra of (a) cellulose microcrystal (CMC) and $\mathrm{CNC}$ (b) $\mathrm{Alg}, \mathrm{CNC} / \mathrm{Alg}, \mathrm{CNC} / \mathrm{Ag} / \mathrm{Alg}$, and Ag/Alg samples.

\subsection{Morphology}

The TEM images of fabricated CNC and AgNPs are presented in Figure 3a,b. As seen from Figure 3a, it confirmed that the lengths and widths of the needle shaped CNC were found 100-500 and 5-30 nm, respectively. The averaged particle size of AgNPs was in the range of $4.8 \mathrm{~nm}$, as revealed in Figure 3b. A typical TEM image of Ag/Alg film, as presented in Figure $3 b$, manifests that spherical AgNPs (the small black dots) are finely dispersed within Alg fibers [40]. When $\mathrm{AgNO}_{3}$ was immersed in Alg solution, $\mathrm{Ag}^{+}$could easily diffuse into Alg fibers and reacted with the fibers via ion exchange with sodium ion in the fibers due to the negatively charged Alg facilitating the attraction of the positively charged $\mathrm{Ag}$ ions by electrostatic attraction [41]. Then, number of $\mathrm{Ag}^{+}$ions decreased in situ, and the formed AgNPs closely deposited in the Alg fibers. Moreover, fine dispersion was observed, indicating that the in situ formed AgNPs could be effectively stabilized by the Alg fibers. Figure 4a shows the dispersed needle-shaped CNC in CNC/Alg film, confirming the mixing of $\mathrm{CNC}$ in the Alg matrix [42]. The TEM image of CNC/Ag/Alg composite, shown in Figure $4 \mathrm{~b}$, confirmed fine dispersion of nanofillers (Ag and $\mathrm{CNC}$ ) in the samples, specifying that Alg acted as reducing agents. Similar results have been previously reported [43]. The arrows in Figure $4 a, b$ indicate the dispersed CNC. The cross-sectional morphology of CNC/Ag/Alg composite film, as observed by FESEM in Figure S1a,b, indicate the existence of spherical AgNPs. EDS analysis, shown in Figure S1c,d, confirms the existence $\mathrm{C}, \mathrm{O}, \mathrm{Ag}$, and $\mathrm{Na}$ elements in the composite film. The OM images of $\mathrm{CMC}$ and $\mathrm{CNC}$ in dry powder form, and $\mathrm{Alg}$, $\mathrm{Ag} / \mathrm{Alg}$, $\mathrm{CNC} / \mathrm{Alg}$, and $\mathrm{CNC} / \mathrm{Ag} / \mathrm{Alg}$ composites in film form are presented in Figure $\mathrm{S} 2$. It is noted that $\mathrm{Ag}$ and $\mathrm{CNC}$ were well-dispersed in the Alg matrix and might lead to improved barrier and mechanical performance. 

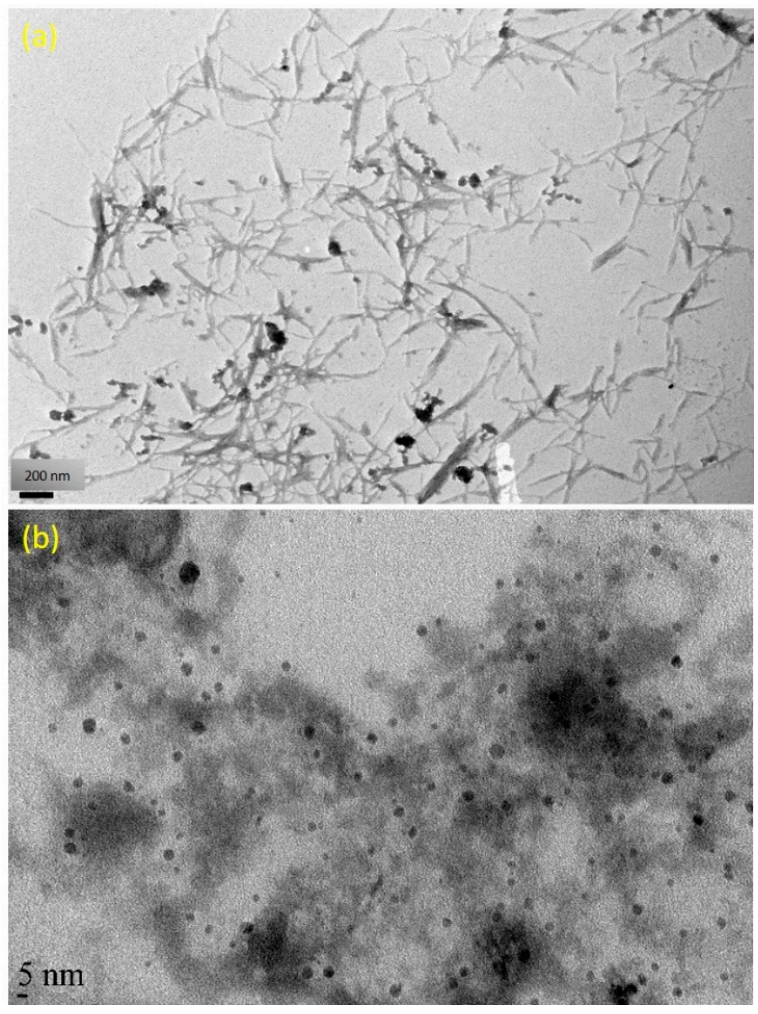

Figure 3. TEM images of (a) CNC and (b) AgNPs in Ag/Alg samples.
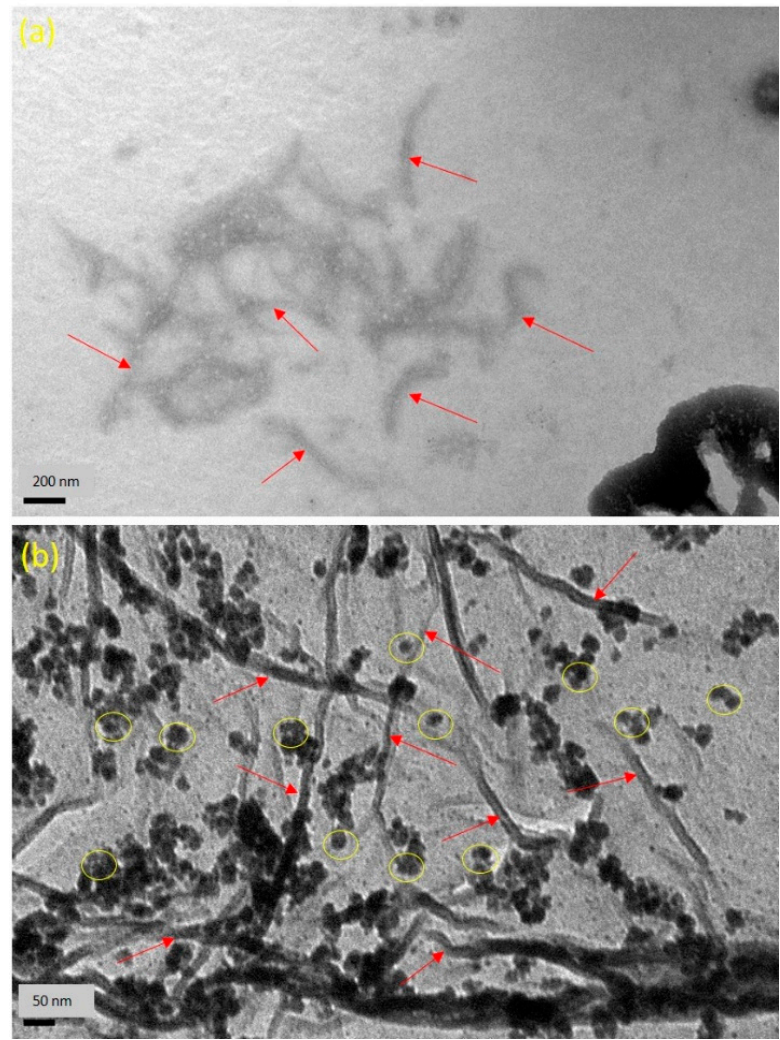

Figure 4. Transmission Electron Microscopy (TEM) images of (a) CNC/Alg and (b) CNC/Ag/Alg composite films. 


\subsection{X-ray Diffraction (XRD)}

Figure 5 exhibits $\mathrm{XRD}$ data $\left(2 \theta=5^{\circ}\right.$ to $\left.80^{\circ}\right)$ of $\mathrm{CMC}, \mathrm{CNC}, \mathrm{Alg}, \mathrm{Ag} / \mathrm{Alg}, \mathrm{CNC} / \mathrm{Alg}$, and $\mathrm{CNC} / \mathrm{Ag} / \mathrm{Alg}$ samples. As shown in the Figure 5, CMC showed four crystalline peaks at $22.6^{\circ}, 15.3^{\circ}, 16.5^{\circ}$, and $34.7^{\circ}$. However, CNC presented crystalline peaks at $23.0^{\circ}, 15.6^{\circ}, 16.4^{\circ}$, and $34.6^{\circ}$, indicating a crystal structure of cellulose I [44]. On the basis of obtained crystallinity indexes (CMC $=0.50, C N C=0.58)$, it is noticed that $\mathrm{CNC}$ is more crystalline than CMC. The two broad peaks of Alg at $16.63^{\circ}$ and 22.35 show its amorphous nature. The Ag/Alg composite films exhibited three XRD peaks at $38.27^{\circ}(111), 43.62^{\circ}$ (200), and $76.72^{\circ}$ (311), which confirmed the existence of Ag in bionanocomposite film [45]. After CNC loading with $\mathrm{Alg}$, the peak $22.9^{\circ}$ of $\mathrm{CNC}$ disappeared [46,47]. As shown in Figure 5, incorporation of $5 \mathrm{wt} . \% \mathrm{CNC}$ decreased the intensity of Alg peaks. The similarity between the XRD curve of CNC/Alg and $\mathrm{CNC}$ suggests that $\mathrm{CNC}$ are well-distributed in polymer solution. The XRD pattern of $\mathrm{CNC} / \mathrm{Ag} / \mathrm{Alg}$ bionanocomposite films is almost the same as that of $\mathrm{Ag} / \mathrm{Alg}$, thereby confirming that $\mathrm{Ag}$ is present in the blends.
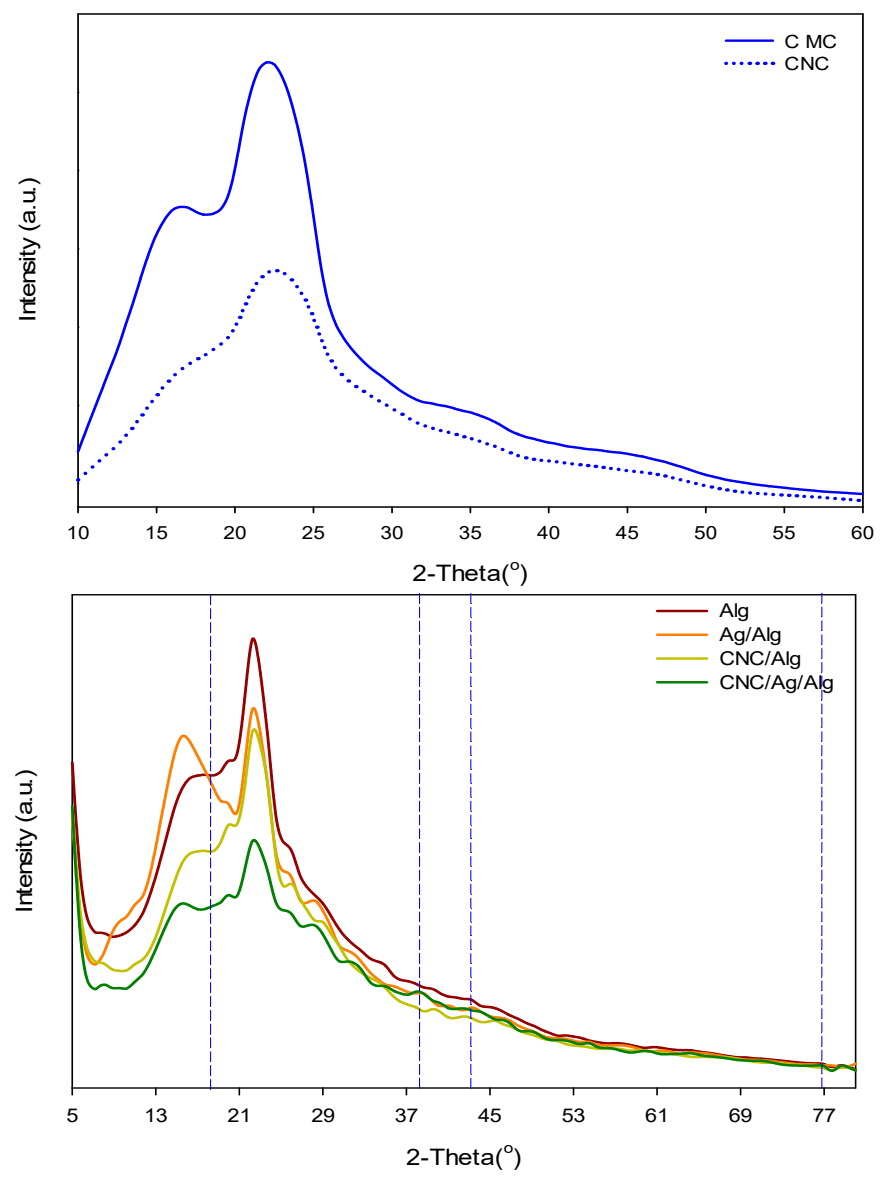

Figure 5. $\mathrm{XRD}$ patterns of $\mathrm{CMC}, \mathrm{CNC}, \mathrm{Alg}, \mathrm{Ag} / \mathrm{Alg}, \mathrm{CNC} / \mathrm{Alg}$, and $\mathrm{CNC} / \mathrm{Ag} / \mathrm{Alg}$ samples.

\subsection{Thermal Properties}

Biomaterials based packaging films are broadly used in the food industry because of their high yield, less handling time, and less production cost, but temperatures lower their stability in terms of degradation. Recently, a paper published by Otoni et al. [48] studied in details for the thermal properties of fruits and vegetable-based food packaging films. The thermal stability of these films can be understood with TGA in terms of integral procedural decomposition temperature (IPDT) values. Proposed by Doyle et al. [49], IPDT is associated with the extent of volatility of polymeric materials 
and has been used to estimate the inherent thermal stability of polymeric materials. IPDT is calculated from Equation (11):

$$
\begin{aligned}
\operatorname{IPDT}\left({ }^{\circ} \mathrm{C}\right) & =\mathrm{A}^{*} \mathrm{~K}^{*}\left(\mathrm{~T}_{\mathrm{f}}-\mathrm{T}_{\mathrm{i}}\right)+\mathrm{T}_{\mathrm{i}}, \\
\mathrm{A}^{*} & =\frac{\mathrm{S}_{1}+\mathrm{S}_{2}}{\mathrm{~S}_{1}+\mathrm{S}_{2}+\mathrm{S}_{3},} \\
\mathrm{~K}^{*} & =\frac{\mathrm{S}_{1}+\mathrm{S}_{2}}{\mathrm{~S}_{1}},
\end{aligned}
$$

where, $A^{*}$ is the area ratio of the total experimental curve defined by the total TGA thermograms. $T_{i}$ and $T_{f}$ are the initial and final experimental temperature, respectively. A presentation of $S_{1}, S_{2}$, and $S_{3}$ for calculating $\mathrm{A}^{*}$ and $\mathrm{K}^{*}$ are provided in a published research paper [50]. Figure $6 \mathrm{a}, \mathrm{b}$ pointed to the TGA/ Differential Thermal Gravimetric Analysis (DTGA) curve of CMC and CNC. As found in the figure, $\mathrm{CMC}$ and $\mathrm{CNC}$ showed almost the same thermal degradation behavior. The degradation at $346{ }^{\circ} \mathrm{C}$ was found due to the burning of cellulose, dehydration, and decomposition of the glycoside units [51]. The IPDT values (presented in Table S1) indicated that CMC is more thermally stable than CNC. Figure $6 c$,d showed the TGA/DTGA curve of Alg and its nanocomposite samples. The thermal degradation of Alg film was previously reported by Oun and Rhim et al. [52]. The degradation at 204-315 ${ }^{\circ} \mathrm{C}$ might be due to the vaporization of glycerol and polymer matrix Alg [52]. A further temperature increase to $700{ }^{\circ} \mathrm{C}$ showed third and fourth peaks at approximately 374 (347-417) ${ }^{\circ} \mathrm{C}$ and 575 (541-627) ${ }^{\circ} \mathrm{C}$, respectively. The TGA/DTGA of Ag/Alg bionanocomposite films showed three-step degradation. Ag/Alg bionanocomposite films variously degraded at $40-112,191-301$, and $346-418{ }^{\circ} \mathrm{C}$, with $\mathrm{T}_{\max }$ values of 54,238 , and $393^{\circ} \mathrm{C}$ identified in the three-step degradation (DTGA, Figure $6 \mathrm{~d}$ ). The degradation showed in TGA/DTGA of (5 wt.\%) CNC/Alg bionanocomposite films occurred in three steps. Specifically, (5 wt.\%) CNC/Alg degraded at 31-105, 205-322, and 527-625 ${ }^{\circ} \mathrm{C}$, with Tmax values of 48,247 , and $572{ }^{\circ} \mathrm{C}$ identified in the three-step degradation (DTGA, Figure 6d). From obtained results, CNC/Alg films showed higher thermal stability comparison to neat polymer matrix and CNC. This behavior is also verified by IPDT (Table S1) values [31]. As shown in the figure, CNC content affected the phase of used Alg films. The first $\left(32-124{ }^{\circ} \mathrm{C}\right)$ and second $\left(124-242{ }^{\circ} \mathrm{C}\right)$ degradation occurred due to water desorption and fiber dehydration [53], respectively. At the end, carbonaceous type materials were removed at $242{ }^{\circ} \mathrm{C}$ [54]. The degradation of $\mathrm{CNC} / \mathrm{Ag} / \mathrm{Alg}$ bionanocomposite films in TGA/DTGA occurred in two steps rather than one. Specially, CNC/Ag/Alg bionanocomposite films degraded at $178-249^{\circ} \mathrm{C}$ and $530-677^{\circ} \mathrm{C}$, with $\mathrm{T}_{\max }$ values of 232 and $622^{\circ} \mathrm{C}$ recognized in the two-step degradation (DTGA, Figure 6d). Furthermore, IPDT values of Alg, Ag/Alg, CNC/Alg, and $\mathrm{CNC} / \mathrm{Ag} / \mathrm{Alg}$ films obtained on the basis of Doyle concept are shown in Table S1. The order of Alg, $\mathrm{Ag} / \mathrm{Alg}$, CNC/Alg, and CNC/Ag/Alg films for IPDT can be represented as

$$
\begin{gathered}
\mathrm{Alg}<\mathrm{CNC} / \mathrm{Alg}<\mathrm{Ag} / \mathrm{Alg}>\mathrm{CNC} / \mathrm{Ag} / \mathrm{Alg} \\
601.934<642.551<1078.890>766.312 .
\end{gathered}
$$

A comparison of the thermograms of $\mathrm{Alg}, \mathrm{Ag} / \mathrm{Alg}, \mathrm{CNC} / \mathrm{Alg}$, and $\mathrm{CNC} / \mathrm{Ag} / \mathrm{Alg}$ films confirmed that the IPDT values were highest for $\mathrm{Ag} / \mathrm{Alg}$ films, thereby indicating that $\mathrm{Ag} / \mathrm{Alg}$ composite films is more thermally stable than $\mathrm{Alg}$, $\mathrm{CNC} / \mathrm{Alg}$, and $\mathrm{CNC} / \mathrm{Ag} / \mathrm{Alg}$ films. 

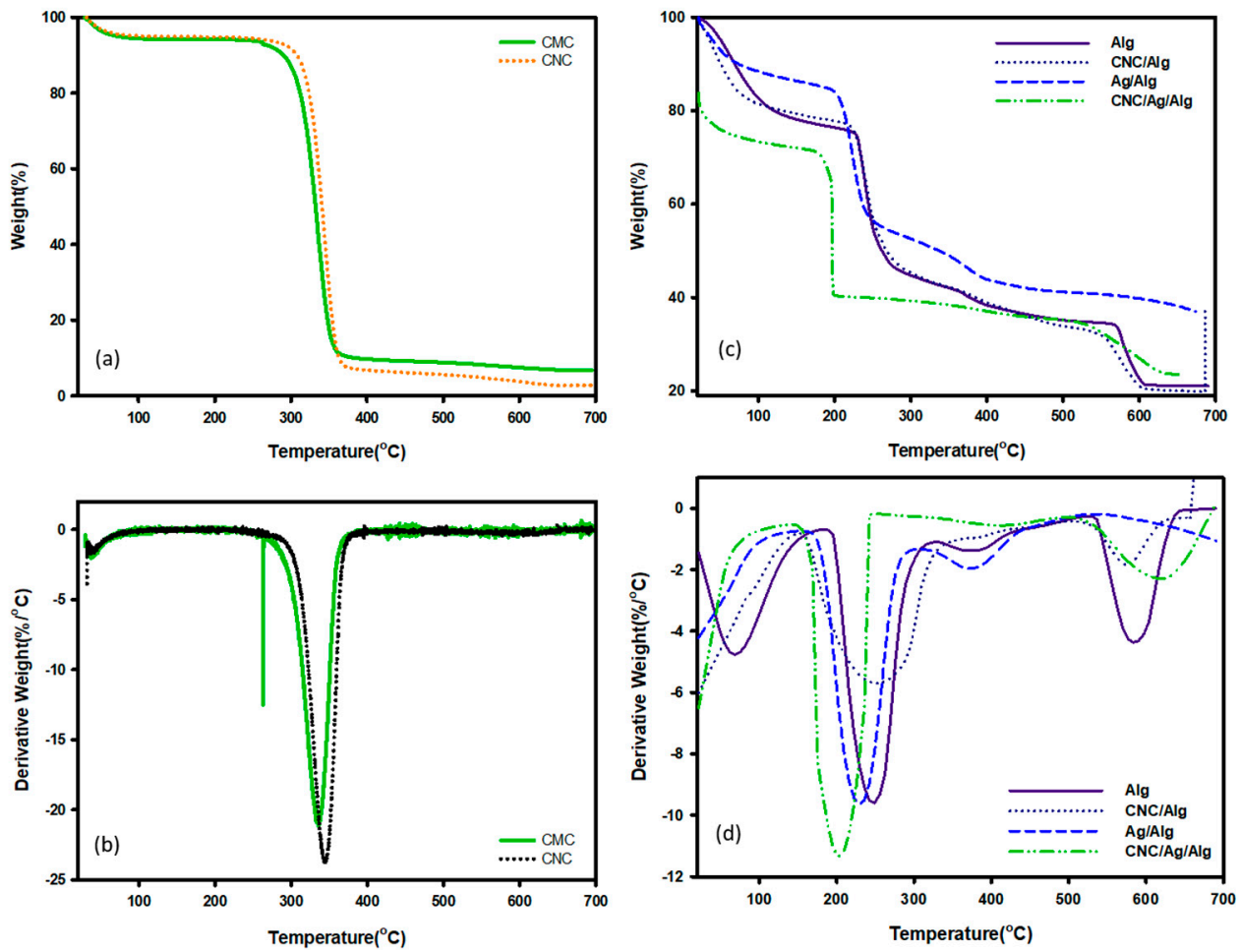

Figure 6. TGA (a,c) and DTGA (b,d) curve of CMC, CNC, Alg, CNC/Alg, Ag/Alg, and $\mathrm{CNC} / \mathrm{Ag} / \mathrm{Alg}$ samples.

\subsection{Water Barrier Properties of the Films}

Lower water solubility of food packaging films is an important property for applications in food protection because water resistance avoided films disintegration during coating of humid food surfaces. The FWS of all used films were presented in Table 1. As shown in the table, Ag/Alg, CNC/Alg, and $\mathrm{CNC} / \mathrm{Ag} / \mathrm{Alg}$ bionanocomposite films exhibited FWS value at 89.39, 61.29, and 56.36 which is lower than neat Alg film (99.20). The low solubility data may be caused by high crystallinity of CNC and their strong hydrogen-bonded network within the Alg matrix [55]. This low solubility of samples can be attributed to the presence of nanoparticles [56,57].

Table 1. Values of thickness, film water solubility (FWS), moisture absorption (MA), water vapor permeation (WVP), Tensile Strength (TS) and Elongation at break (EB) (\%) for Alg, Ag/Alg, CNC/Alg, and $\mathrm{CNC} / \mathrm{Ag} / \mathrm{Alg}$ films.

\begin{tabular}{|c|c|c|c|c|c|c|}
\hline $\begin{array}{l}\text { Sample } \\
\text { Code }\end{array}$ & $\begin{array}{l}\text { Thickness } \\
\qquad(\mu \mathrm{m})\end{array}$ & FWS & MA (\%) & $\begin{array}{c}\text { WVP } \\
\left(\times 10^{-11} \mathrm{gm}^{-1} \mathrm{~s}^{-1} \mathrm{~Pa}^{-1}\right)\end{array}$ & $\begin{array}{c}\text { TS } \\
(\mathrm{MPa})\end{array}$ & EB (\%) \\
\hline Alg & 10 & 99.20 & 18.87 & 6.53 & 25.60 & 17.10 \\
\hline Ag/Alg & 11 & 89.39 & 12.33 & 4.20 & 40.30 & 13.20 \\
\hline $\mathrm{CNC} / \mathrm{Alg}$ & 11 & 61.29 & 12.22 & 5.40 & 35.50 & 14.30 \\
\hline $\mathrm{CNC} / \mathrm{Ag} / \mathrm{Alg}$ & 12 & 56.36 & 13.24 & 4.60 & 39.40 & 14.70 \\
\hline
\end{tabular}

The moisture absorption property of biopolymer food packaging films depends on water sensitivity and hygroscopic properties. Sometimes, these properties restricted the application of Alg film. In this regard, $\mathrm{Alg}$ was reinforced with $\mathrm{Ag}$ and $\mathrm{CNC}$. So, the chances to absorb moisture were decreased due to interaction of $\mathrm{Alg}, \mathrm{Ag}$, and CNC. As illustrated in Table 1, the MA value of the $\mathrm{Ag} / \mathrm{Alg}$ bionanocomposite films decreased from $18.87 \%$ to $12.33 \%$ because of the presence of lesser number of $-\mathrm{OH}$ groups of the Alg matrix that contributed in bonding with Ag. The provided data in Table 1 confirmed that the MA of neat Alg films decreased from $18.87 \%$ to $12.22 \%$ after loading of (5 wt. $\%$ ) $\mathrm{CNC}$. It might be due to the availability of lesser number of -OH group for hydrogen bonding with 
$\mathrm{CNC}$ (3-D network hard materials). In the case of $\mathrm{CNC} / \mathrm{Ag} / \mathrm{Alg}$ composite films, a decrement of MA was also recorded from $18.87 \%$ to $13.24 \%$ compared with neat Alg.

Water vapor permeation (WVP) provides an information about the water transfer from the food to its environment. The WVP of Alg, Ag/Alg, CNC/Alg, and CNC/Ag/Alg are presented in Table 1. From the table, it is clear that the WVP of CNC/Alg bionanocomposite films was higher than that of $\mathrm{Ag} / \mathrm{Alg}$ bionanocomposite films, and the WVP of CNC/Ag/Alg bionanocomposite films was found in between both. It might be due to the presence of CNC and AgNPs structure. The needle shaped CNC distributed in the Alg might improve an effective tortuous route [31] for vapor diffusion process than AgNPs. Published research papers [11,34] also described that the water barrier behaviors were improved if the nanofillers are less permeable than polymer matrix.

\subsection{Thickness and Mechanical Properties of Films}

The thickness of packaging films generally depend on the three factors [58]: structure, composition, and interaction of the solutions. Meanwhile, the thickness of the synthesized films (Table 1) varied from $10 \mu \mathrm{m}$ to $12 \mu \mathrm{m}$. Among the films, neat Alg film exhibited least thickness (10 $\mu \mathrm{m})$. However, $\mathrm{CNC}$ reinforced Alg films (CNC/Alg) enhanced the thickness to $11 \mu \mathrm{m}$. The prepared CNC/Ag/Alg bionanocomposite films showed a maximum thickness of $12 \mu \mathrm{m}$. The mechanical behavior of packaging films is a highly important property for the film to maintain its authenticity and bear environmental stress during packaging application [59]. This behavior is generally studied in terms of Tensile Strength (TS) (strength) and Elongation at break(EB) (flexibility). These features support the correlation of the mechanical properties of films to their compositions and chemical structures. The TS and EB (\%) of the Alg films were valued at $25.60 \mathrm{MPa}$ and $17.10 \%$, respectively, thereby indicating that the $\mathrm{Alg}$ film is mechanically stronger than PLA films [60]. However, the flexibility of the Alg film is particularly low. From Table 1, it is revealed that the TS of Ag/Alg, CNC/Ag/Alg, and CNC/Alg bionanocomposite films was found 57.42, 53.91, and 38.67\%, respectively, higher than Alg film. The TS of used films are comparable with LDPE (8-10 MPa), HDPE (19-31 MPa), EVOH (6-19 MPa), PCL (4 MPa), PS (31-49 MPa), PLA (45 MPa), PVC (42-55 MPa), PP (27-98 MPa), and PET (157-177 MPa) plastic films. Huq et al. [31] reported that $5 \mathrm{wt} . \% \mathrm{CNC}$ loading significantly increased the mechanical and barrier properties of the Alg-based matrix. Deepa et al. [30] found that the incorporation of $10 \mathrm{wt} . \% \mathrm{CNF}$ into the Alg matrix improved the mechanical properties. Shankar et al. [40] observed that $\mathrm{Ag} / \mathrm{Alg}$ bionanocomposite films exhibited greater TS (63.2 MPa) than the Alg (56.8 MPa). A similar improvement in $\mathrm{TS}$ of $\mathrm{Alg}$ by loading $\mathrm{Ag}, \mathrm{CNC}$, clay, and graphene oxide were also reported in numerous papers $[30,31,40,61,62]$. The increase in mechanical strength of the nanocomposite films is mainly attributed to the physical attraction between the filler and the polymer matrix $[63,64]$. Huq et al. [31] reported that the high TS of the Alg-based bionanocomposite films is due to good interfacial interaction between the nanofillers and Alg-based matrix because of similar polysaccharide structures of cellulose and Alg. The other explanation for the improvement in TS of the Alg-based bionanocomposite films may be the increase of contact area between Alg and nanoparticles [63]. Some other research groups [65] noticed that AgNPs based biocomposites were performed by interactions between the hydroxyl groups of biopolymer and the partial positive charge on the surface of the AgNPs. On the other hand, EB (\%) of CNC/Ag/Alg, CNC/Alg, and Ag/Alg decreased by $14.70 \%$, $14.30 \%$, and $13.20 \%$, respectively (Table 1 ). The obtained EB (\%) of composite films is comparable with PS (2-3\%), PVC (20-180\%), HDPE (20-50\%) [66], and PVDC (10-40\%) films. A similar trend in EB was also observed by Rhim et al. [63] and Mathew et al. [64]. They explained that the decrease in EB of bionanocomposite films is due to decreased ductility of the polymer by using nanoparticles. The tensile strength of $\mathrm{CNC} / \mathrm{Alg}$, $\mathrm{Ag} / \mathrm{Alg}$, and $\mathrm{CNC} / \mathrm{Ag} / \mathrm{Alg}$ bionanocomposite films maintained a tensile nature better than the Alg. Thus, the used nanofillers, such as $\mathrm{Ag}, \mathrm{CNC}$, and $\mathrm{Ag} / \mathrm{CNC}$, can be used as a reinforcing agents in the $\mathrm{Alg}$ films. 


\subsection{Color Analysis}

The physical appearance of the food product affects the consumer preferences. Therefore, the color of the packaging films directed a great effect in food industry. The obtained color variables $\mathrm{L}$, $\mathrm{a}, \mathrm{b}$, and $\Delta \mathrm{E}$ are presented in Table 2. As seen from Table 2, Ag/Alg and CNC/Ag/Alg composite films showed a darker color than Alg as revealed from the decreased values of $\mathrm{L}$. The $\mathrm{Ag} / \mathrm{Alg}$ and $\mathrm{CNC} / \mathrm{Ag} / \mathrm{Alg}$ films showed brown color as detected from the increase of both ' $b$ ' and ' $a$ '. The value of total color difference $(\Delta \mathrm{E})$ of AgNPs incorporated composite films $(\mathrm{Ag} / \mathrm{Alg}$ and $\mathrm{CNC} / \mathrm{Ag} / \mathrm{Alg})$ increased dramatically. This is might be due to the development of brown color caused by the plasmonic effect of AgNPs [67]. The plasmonic effect of AgNPs was presented in the absorption spectra of the films, as displayed in Figure 7.

Table 2. Opacity and color variables of $\mathrm{Alg}, \mathrm{CNC} / \mathrm{Alg}$, Ag/Alg, and CNC/Ag/Alg films.

\begin{tabular}{cccccc}
\hline Sample Code & Opacity (Abs600/mm) & $\mathbf{L}$ & $\mathbf{a}$ & $\mathbf{b}$ & $\boldsymbol{\Delta} \mathbf{E}$ \\
\hline Alg & 1.37 & 93.68 & -1.04 & 2.772 & 2.53 \\
CNC/Ag & 11.43 & 93.37 & -0.1 & 4.77 & 4.22 \\
Ag/Alg & 20.84 & 32.95 & 9.33 & 14.02 & 65.02 \\
CNC/Ag/Ag & 37.70 & 36.92 & 29.95 & 28.10 & 71.77 \\
\hline
\end{tabular}
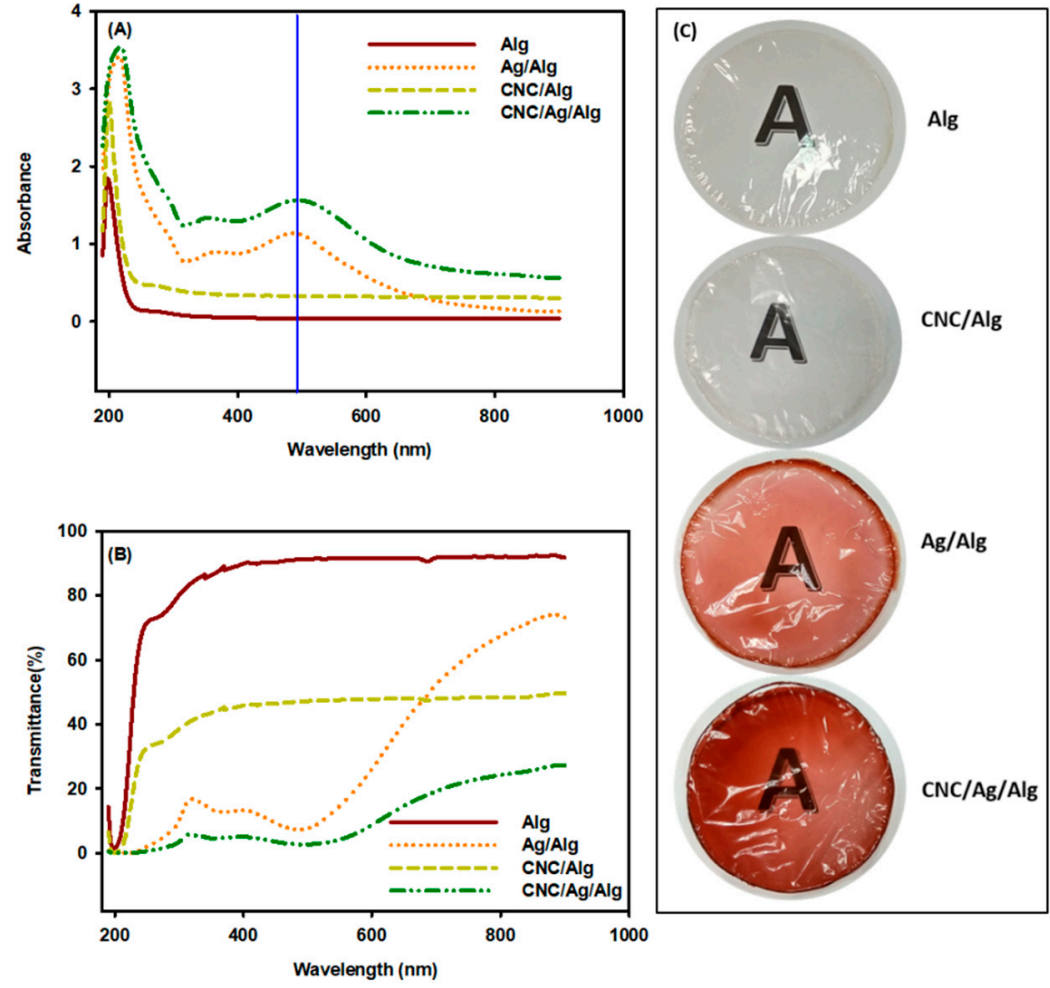

Figure 7. Ultraviolet (UV) spectra for (A) absorbance, (B) transmittance, and (C) visual observation (transparency) of biocomposite films.

\subsection{Opacity and $U V$ Visibility of Films}

The ability of the food packaging films to block the UV light is an important attribute for food products. Thus, the transmission of ultraviolet $(200-400 \mathrm{~nm})$ and visible light $(400-700 \mathrm{~nm})$ through food packaging films played an important role for tracing proper package. The biopolymer based transparent food packaging films secure the pictorial confirmation of food content, which is an important reason that affects the consumer's sense of food quality. Opacity is a key factor that controls 
the quality of packaging films. As presented in Table 2, the opacity of all used films showed the following order:

$$
\begin{gathered}
\mathrm{Alg}>\mathrm{CNC} / \mathrm{Alg}>\mathrm{Ag} / \mathrm{Alg}>\mathrm{CNC} / \mathrm{Ag} / \mathrm{Alg} \\
1.37>11.43>20.84>37.70
\end{gathered}
$$

The optical properties of $\mathrm{Alg}, \mathrm{Ag} / \mathrm{Alg}, \mathrm{CNC} / \mathrm{Alg}$, and $\mathrm{CNC} / \mathrm{Ag} / \mathrm{Alg}$ observed by UV-Vis absorption spectrophotometry are shown in Figure 7. No absorption band was found in the 300-650 $\mathrm{nm}$ region for Alg and CNC/Alg (Figure 7A). By contrast, an absorption band at $491 \mathrm{~nm}$ was observed in Ag/Alg and $\mathrm{CNC} / \mathrm{Ag} / \mathrm{Alg}$ (Figure 7A). Fundamentally, AgNPs exhibited a surface plasmon resonance (SPR) band between 350 and $500 \mathrm{~nm}$ [68]. The SPR band of $\mathrm{Ag} / \mathrm{Alg}$ and $\mathrm{CNC} / \mathrm{Ag} / \mathrm{Alg}$ is attributed to the presence of AgNPs. Ag/Alg showed no band shift compared with CNC/Ag/Alg due to surface plasmon resonance. This occurrence implied AgNPs are well-dispersed within the Alg matrix; otherwise, band shift occurs due to AgNPs aggregation [69,70]. Evidently, the well dispersion of AgNPs in Ag/Alg and $\mathrm{CNC} / \mathrm{Ag} / \mathrm{Alg}$ was presented in TEM images Figure 4a,c. Figure 7B illustrates that the UV light transmittance of the Alg nanocomposite films continuously decreases compared with that of Alg films due to the UV-shielding ability of $\mathrm{Ag}, \mathrm{CNC}$, and $\mathrm{CNC} / \mathrm{Ag}$. The decline in transmittance with $\mathrm{Ag}$, $\mathrm{CNC}$, and $\mathrm{CNC} / \mathrm{Ag}$ contents is symbolic of the uniform distribution of $\mathrm{Ag}, \mathrm{CNC}$, and $\mathrm{CNC} / \mathrm{Ag}$ in the Alg matrix [34]. As shown in the figure, the UV light transmittances of $\mathrm{Alg}, \mathrm{Ag} / \mathrm{Alg}, \mathrm{CNC} / \mathrm{Alg}$, and $\mathrm{CNC} / \mathrm{Ag} / \mathrm{Alg}$ at $800 \mathrm{~nm}$ were valued at $92 \%, 67.37 \%, 48.27 \%$, and $24.18 \%$, respectively. The decrease in transmittance in all used films retained optical transparency, and no visual collections were detected (digital images of films presented in Figure 7C). The order of optical transparency (Table S2) of used films is as follows:

$$
\begin{gathered}
\mathrm{Alg}>\mathrm{CNC} / \mathrm{Alg}>\mathrm{Ag} / \mathrm{Alg}>\mathrm{CNC} / \mathrm{Ag} / \mathrm{Alg} \\
90.77>46.88>32.85>12.11
\end{gathered}
$$

Although the $\mathrm{Ag} / \mathrm{Alg}, \mathrm{CNC} / \mathrm{Alg}$, and $\mathrm{CNC} / \mathrm{Ag} / \mathrm{Alg}$ composite films showed lower transparent results compared to neat $\mathrm{Alg}$ film which is good feature for packaging materials. The light transmittance at different wavelengths of $\mathrm{Ag} / \mathrm{Alg}, \mathrm{CNC} / \mathrm{Alg}$, and $\mathrm{CNC} / \mathrm{Ag} / \mathrm{Alg}$ bionanocomposite in the UV region was presented in Table S2. From Figure 7A, it was found that the CNC/Ag/Alg bionanocomposite films had more UV resistance power comparison to others used films. It might be due to uniform-homogenous dispersion of CNC and Ag nanoparticles in Alg matrix. The Hosseini group [71] and Arfat group [72] reported that UV light barrier property of biopolymer films can be improved by adding nanofiller. From the above results, it is clear that that $\mathrm{CNC} / \mathrm{Ag} / \mathrm{Alg}$ bionanocomposite films can be used as a UV barrier in food packaging materials.

\subsection{Biodegradation of Films in Soil}

Biodegradability test is a highly important tool to recognize the environmental compatibility of materials. The biodegradability of food materials in the soil is already reported by many research group $[73,74]$. Specifically, the renewable biopolymer food packaging films showed an interesting biodegradable nature with soil. The biodegradation test of the prepared packaging films is assigned via soil burial degradation method for 8 weeks (Figure 8). The biodegradability results of Alg, CNC/Alg, $\mathrm{Ag} / \mathrm{Alg}$, and $\mathrm{CNC} / \mathrm{Ag} / \mathrm{Alg}$ films are presented in Figure 8. Evidently, the biodegradability of Alg films increased to $77.27 \%$ as the burial time increased in the soil for 8 weeks. The biodegradability rate of (5 wt.\%) CNC/Alg bionanocomposite films was found to decrease in soil compared to Alg. It might be due to a strong interaction development between the matrix and the filler due to the homogeneous dispersion of CNC nanoparticles in the Alg matrix. Thus, the film degradation becomes complex due to difficulty in breaking the strong bonds between the Alg matrix and the CNC [30]. Meanwhile, $\mathrm{Ag} / \mathrm{Alg}$ and $\mathrm{CNC} / \mathrm{Ag} / \mathrm{Alg}$ films showed a slight decrease in biodegradability behavior compared with $\mathrm{Alg}$ and $\mathrm{CNC} / \mathrm{Ag}$ films due to the existence of metal (Ag). 


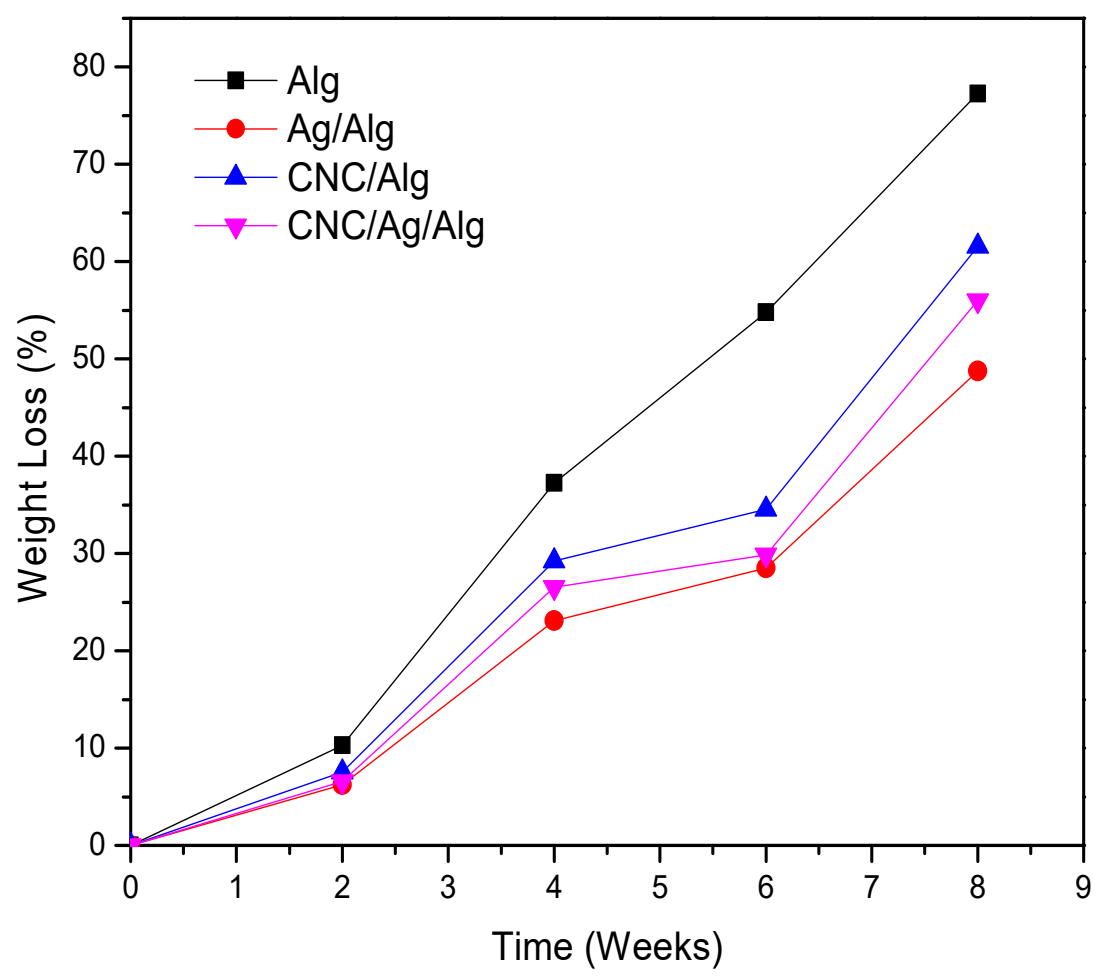

Figure 8. Biodegradation curves for $\mathrm{Alg}$, $\mathrm{Ag} / \mathrm{Alg}, \mathrm{CNC} / \mathrm{Alg}$, and $\mathrm{CNC} / \mathrm{Ag} / \mathrm{Alg}$ films.

\section{Discussion}

In this article, the needle-shaped CNC was prepared from CMC using acid hydrolysis and was used as reinforcement materials in bionanocomposites on the basis of Ag/Alg mixture. The solution blend technique was applied for fabricating CNC/Ag/Alg composite films. FTIR revealed that CNC and AgNPs interacted with Alg through hydrogen bonding, and good miscibility was developed among Alg, CNC, and Ag. The AgNPs-included composite films showed a specific plasmonic effect on the AgNPs with maximum light absorption at $491 \mathrm{~nm}$ and all the composite films, especially composed of AgNPs, showed the UV barrier property. The improved UV barrier property of the composite film can be used as a UV-screening food packaging film. Mechanical strength (determined by the TS), water barrier property, and thermal stability (determined by TGA analysis) of all the nanocomposite films increased significantly. The biodegradability of Alg and CNC/Alg films was found higher than other samples due to the absence of Ag metal. Based on the obtained results, the synthesized biodegradable nanocomposite films have the potential to be used as a food packaging material by using their barrier (water and UV) properties.

Supplementary Materials: The following are available online at http://www.mdpi.com/2079-4991/9/11/1523/s1, Table S1: Thermal stability of CMC, CNC, Alg, CNC/Alg, Ag/Alg and, CNC/Ag/Alg samples, Table S2: Light Transmittance and transparency of control and bionanocomposite films, Figure S1: Cross-sectional FESEM image of CNC/Ag/Alg (a \& b), FESEM-EDS of CNC/Ag/Alg (c and d), and (e) EDX elemental mapping of CNC/Ag/Alg nanocomposite for the following elements: (f) $\mathrm{C}$, (g) $\mathrm{O}$, (h) Ag, and (i) Na, Figure S2: OM images of (a) CMC (b) $\mathrm{CNC}$ in dry powder form, (c) Alg (d) Ag/Alg (e) CNC/Alg (f) CNC/Ag/Alg in film form at Magnification 20x.

Author Contributions: M.Y. did the experimental work, analyzed the results, and wrote the whole manuscript. F.C.C. (project leader) advised experimental techniques and revised the manuscript. Y.K.L. assisted the biodegradation test. All authors have read and approved the final manuscript.

Funding: This research received no external funding.

Acknowledgments: The authors thank to Chang Gung Memorial Hospital (CMRPD2J0081/BMRP392) for financial support. The financial support and Post-doctoral fellowship from Ministry of Science and Technology (Taiwan) under contracts MOST 106-2221-E-182-058-MY3 and MOST 108-2811-E-182-500 are appreciated as well.

Conflicts of Interest: The authors declare no conflicts of interest. 


\section{References}

1. Sorrentino, A.; Gorrasi, G.; Vittoria, V. Potential perspectives of bio-nanocomposites for food packaging applications. Trends Food Sci. Technol. 2007, 18, 84-95. [CrossRef]

2. Padil, V.V.T.; Senan, C.; Wacławek, S.; Cerník, M.; Agarwal, S.; Varma, R.S. Bioplastic fibers from gum arabic for greener food wrapping applications. ACS Sustain. Chem. Eng. 2019, 7, 5900-5911. [CrossRef]

3. Behera, K.; Chang, Y.H.; Chiu, F.C.; Yang, J.C. Characterization of poly (lactic acid) s with reduced molecular weight fabricated through an autoclave process. Polym. Test. 2017, 60, 132-139. [CrossRef]

4. Xie, H.; Xiang, C.; Lia, Y.; Wang, L.; Zhang, Y.; Song, Z.; Ma, X.; Lu, X.; Lei, Q.; Fang, W. Fabrication of ovalbumin/K-carrageenan complex nanoparticles as a novel carrier for curcumin delivery. Food Hydrocoll. 2019, 89, 111-121. [CrossRef]

5. Ghosh, M.; Sternfeld, M.H.; Grinberg, I.; Abramovich, L.A. Injectable alginate-peptide composite hydrogel as a scaffold for bone tissue regeneration. Nanomaterials 2019, 9, 497. [CrossRef] [PubMed]

6. Cavallaro, G.; Lazzara, G.; Milioto, S.; Parisi, F.; Evtugyn, V.; Rozhina, E.; Fakhrullin, R. Nanohydrogel Formation within the Halloysite Lumen for Triggered and Sustained Release. ACS Appl. Mater. Interfaces 2018, 10, 8265-8273. [CrossRef] [PubMed]

7. Lisuzzo, L.; Cavallaro, G.; Milioto, S.; Lazzara, G. Layered composite based on halloysite and natural polymers: A carrier for the $\mathrm{pH}$ controlled release of drugs. New J. Chem. 2019, 4, 10887-10893. [CrossRef]

8. Draget, K.I.; Braek, G.S.; Smidsrod, O. Alginic acid gels: The effect of alginate chemical composition and molecular weight. Carbohydr. Polym. 1994, 25, 31-38. [CrossRef]

9. Fabra, M.J.; Talens, P.; Chiralt, A. Effect of alginate and -carrageenan on tensile properties and water vapor permeability of sodium caseinate-lipid based films. Carbohydr. Polym. 2008, 74, 419-426. [CrossRef]

10. Shankar, S.; Kasapis, S.; Rhim, J.W. Alginate-based nanocomposite films reinforced with halloysite nanotubes functionalized by alkali treatment and zinc oxide nanoparticles. Int. J. Biol. Macromol. 2018, 118, 1824-1832. [CrossRef]

11. Rhim, J.W.; Wang, L.F. Preparation and characterization of carrageenan-based nanocomposite films reinforced with clay mineral and silver nanoparticles. Appl. Clay Sci. 2014, 97, 174-181. [CrossRef]

12. Li, Y.; Guo, M.X.; He, L.; Huang, C.Z.; Li, Y.F. Green one-pot synthesis of silver nanoparticles/metal-organic gels hybrid and its promising SERS application. ACS Sustain. Chem. Eng. 2019, 7, 5292-5299. [CrossRef]

13. Sharma, S.; Sanpui, P.; Chattopadhyay, A.; Ghosh, S.S. Fabrication of antibacterial silver nanoparticle-Sodium alginate-Chitosan composite films. RSC Adv. 2012, 2, 5837-5843. [CrossRef]

14. Shao, Y.; Wu, C.; Wu, T.; Yuan, C.; Chen, S.; Ding, T.; Ye, X.; Hu, Y. Green synthesis of sodium alginate-silver nanoparticles and their antibacterial activity. Int. J. Biol. Macromol. 2018, 111, 1281-1292. [CrossRef]

15. Ramachandraiah, K.; Gnoc, N.T.B.; Chin, K.B. Biosynthesis of silver nanoparticles from persimmon byproducts and incorporation in biodegradable sodium alginate thin film. J. Food Sci. 2017, 82, 2329-2336. [CrossRef]

16. Liu, Y.; Chen, S.; Zhong, L.; Wu, G. Preparation of high stable silver nanoparticle dispersion by using sodium alginate as a stabilizer under gamma radiation. Radiat. Phys. Chem. 2009, 78, 251-255. [CrossRef]

17. Narayanan, K.B.; Han, S.S. Dual-crosslinked poly (vinyl alcohol)/sodium alginate/silver nanocomposite beads-A promising antimicrobial material. Food Chem. 2017, 234, 103-110. [CrossRef]

18. Tankhiwale, R.; Bajpai, S.K. Graft copolymerization onto cellulose-based filter paper and its further development as silver nanoparticles loaded antibacterial food-packaging material. Colloids Surf. B 2009, 69, 164-168. [CrossRef]

19. Yoksan, R.; Chirachanchai, S. Silver nanoparticle-loaded chitosan-starch based films: Fabrication and evaluation of tensile, barrier and antimicrobial properties. Mater. Sci. Eng. C 2010, 30, 891-897. [CrossRef]

20. Rubio, A.L.; Fabra, M.J.; Sanz, M.M. Food Packaging Based on Nanomaterials. Nanomaterials 2019, 9, 1224. [CrossRef]

21. Tang, S.; Wang, Z.; Li, P.; Li, W.; Li, C.; Wang, Y.; Chu, P.K. Degradable and photocatalytic antibacterial $\mathrm{Au}-\mathrm{TiO}_{2} /$ Alginate nanocomposite films for active food packaging. Nanomaterials 2018, 8, 930. [CrossRef] [PubMed]

22. Siracusa, V.; Romani, M.; Gigli, C.; Mannozzi Cecchini, J.P.; Tylewicz, U.; Lotti, N. Characterization of active edible films based on citral essential oil, alginate and pectin. Materials 2018, 11, 1980. [CrossRef] [PubMed]

23. Klemm, D.; Heublein, B.; Fink, H.P.; Bohn, A. Cellulose: Fascinating biopolymer and sustainable raw material. Angew. Chem. Int. Ed. 2005, 44, 3358-3393. [CrossRef] [PubMed] 
24. Jordan, J.H.; Easson, M.W.; Condon, B.D. Alkali Hydrolysis of Sulfated Cellulose Nanocrystals: Optimization of Reaction Conditions and Tailored Surface Charge. Nanomaterials 2019, 9, 1232. [CrossRef]

25. Habibi, Y.; Lucia, L.A.; Rojas, O.J. Cellulose Nanocrystals: Chemistry, Self-Assembly, and Applications. Chem. Rev. 2010, 110, 3479-3500. [CrossRef]

26. Jeevananda, T. Synthesis and characterization of microcrystalline cellulose powder. Indian J. Eng. Mater. Sci. 1997, 4, 38-40.

27. Thambiraj, S.; Shankaran, D.R. Preparation and physicochemical characterization of cellulose nanocrystals from industrial waste cotton. Appl. Surf. Sci. 2017, 412, 405-416. [CrossRef]

28. Liu, H.; Liu, D.; Yao, F.; Wu, Q. Fabrication and properties of transparent polymethylmethacrylate/cellulose nanocrystals composite. Bioresour. Technol. 2010, 10, 56. [CrossRef]

29. Rescignano, N.; Fortunati, E.; Montesano, S.; Emiliani, C.; Kenny, J.M.; Martino, S.; Armentano, I. PVA bio-nanocomposites: A new take-off using cellulose nanocrystals and PLGA nanoparticles. Carbohydr. Polym. 2014, 99, 47-58. [CrossRef]

30. Deepa, B.; Abraham, E.; Pothan, L.A.; Cordeiro, N.; Faria, M.; Thomas, S. Biodegradable Nanocomposite Films Based on Sodium Alginate and Cellulose Nanofibrils. Materials 2016, 9, 50. [CrossRef]

31. Huq, T.; Salmieri, S.; Khan, A.; Kha, R.A.; Tien, C.L.; Riedl, B.; Fraschini, C.; Bouchard, J.; Calderon, J.U.; Kamal, M.R.; et al. Nanocrystalline cellulose (NCC) reinforced alginate based biodegradable nanocomposite film. Carbohydr. Polym. 2012, 90, 1757-1763. [CrossRef] [PubMed]

32. Dong, F.; Li, S. Wound dressings based on chitosan-dialdehyde cellulose nanocrystals-silver nanoparticles: Mechanical strength. Polymers 2018, 10, 673. [CrossRef] [PubMed]

33. Yang, G.; Yao, Y.; Wang, C. Green synthesis of silver nanoparticles impregnated bacterial cellulose-alginate composite film with improved properties. Mater. Lett. 2017, 209, 11-14. [CrossRef]

34. Yadav, M.; Chiu, F.C. Cellulose nanocrystals reinforced k-carrageenan based UV resistant transparent bionanocomposite films for sustainable packaging applications. Carbohydr. Polym. 2019, 211, 181-194. [CrossRef]

35. ASHRAE. ASHRAE Handbook, Fundamentals; American Society of Heating and Refrigerating and Air conditioning, Engineers, Inc.: New York, NY, USA, 1997.

36. Martucci, J.F.; Ruseckaite, R.A. Biodegradation of three-layer laminate films based on gelatin under indoor soil conditions. Polym. Degrad. Stab. 2009, 94, 1307-1313. [CrossRef]

37. Pascalau, V.; Popescu, V.; Popescu, G.L.; Dudescu, M.C.; Borodi, G.; Dinescu, A.; Perhait, I.; Paul, M. The alginate/k-carrageenan ratio's influence on the properties of the cross-linked composite films. J. Alloys Compd. 2012, 536, S418-S423. [CrossRef]

38. Kora, A.J.; Sashidhar, R.B.; Arunachalam, J. Gum kondagogu (Cochlospermum gossypium): A template for the green synthesis and stabilization of silver nanoparticles with antibacterial application. Carbohydr. Polym. 2010, 82, 670-679. [CrossRef]

39. Xu, X.; Li, B.; Kennedy, J.F.; Xie, B.J.; Huang, M. Characterization of konjac glucomannane gellan gum blend films and their suitability for release of nisin incorporated therein. Carbohydr. Polym. 2007, 70, 192-197. [CrossRef]

40. Shankar, S.; Wang, L.F.; Rhim, J.W. Preparations and characterization of alginate/silver composite films: Effect of types of silver particles. Carbohydr. Polym. 2016, 146, 208-216. [CrossRef]

41. Zhao, X.; Li, Q.; Li, X.; Xia, Y.; Wang, B.; Zhao, Z. Antibacterial activity and in vitro cytotoxicity evaluation of alginate-AgNP fibers. Text. Res. J. 2016, 87, 1377-1386. [CrossRef]

42. Ni, X.; Wang, J.; Yue, Y.; Cheng, W.; Wang, D.; Han, G. Enhanced Antibacterial Performance and Cytocompatibility of Silver Nanoparticles Stabilized by Cellulose Nanocrystal Grafted with Chito-Oligosaccharides. Materials 2018, 11, 1339. [CrossRef] [PubMed]

43. Dawson, N.J.; Spinella, S.; Kyle, C.K.C.; Maiorana, A.; Qian, Q.; Hepworth, V.; Gross, R.A.; Singer, K.D. Optical interactions of silver nanoparticle decorated cellulose nanocrystals created from a one-pot reduction method. J. Appl. Phys. 2017, 121, 095502. [CrossRef]

44. Khili, F.; Borges, J.; Almeida, P.L.; Boukherroub, R.; Omrani, A.D. Extraction of Cellulose Nanocrystals with Structure I and II and Their Applications for Reduction of Graphene Oxide and Nanocomposite Elaboration. Waste Biomass Valoriz. 2018, 10, 1913-1927. [CrossRef]

45. Gong, P.; Li, H.; He, X.; Wang, K.; Hu, J.; Tan, W.; Zhang, S.; Yang, X. Preparation and antibacterial activity of $\mathrm{Fe}_{3} \mathrm{O}_{4} @ \mathrm{Ag}$ nanoparticles. Nanotechnology 2007, 18, 285604. [CrossRef] 
46. Arrieta, M.P.; Fortunati, E.; Dominici, F.; Lopez, J.; Kenny, J.M. Bionanocomposite films based on plasticized PLA-PHB/cellulose nanocrystal blends. Carbohydr. Polym. 2015, 121, 265-275. [CrossRef] [PubMed]

47. Cao, X.; Chen, Y.; Chang, P.R.; Muir, A.D.; Falk, G. Starch-based nanocomposites reinforced with flax cellulose nanocrystals. Express Polym. Lett. 2008, 2, 502-510. [CrossRef]

48. Otoni, C.G.; Bustillos, R.J.A.; Azeredo, H.M.C.; Lorevice, M.V.; Moura, M.R.; Mattoso, L.H.C.; McHugh, T.H. Recent Advances on Edible Films Based on Fruits and Vegetables: A Review. Compr. Rev. Food Sci. Food Saf. 2017, 16, 1151-1169. [CrossRef]

49. Doyle, C.D. Estimating Thermal Stability of Experimental Polymers by Empirical Thermogravimetric Analysis. Anal. Chem. 1961, 33, 77. [CrossRef]

50. Yadav, M.; Sand, A.; Behari, K. Synthesis and properties of a water soluble graft (chitosan-g-2-acrylamidoglycolic acid) copolymer. Int. J. Biol. Macromol. 2012, 50, 1306-1314. [CrossRef]

51. Vasconcelos, N.F.; Feitosa, J.P.A.; Gama, F.M.P.; Morais, J.P.S.; Andrade, F.K.; Filho, M.S.M.S.; Rosa, M.F. Bacterial cellulose nanocrystals produced under different hydrolysis conditions: Properties and morphological features. Carbohydr. Polym. 2017, 155, 425-431. [CrossRef]

52. Oun, A.A.; Rhim, J.W. Preparation and characterization of sodium carboxymethyl cellulose/cotton linter cellulose nanofibril composite films. Carbohydr. Polym. 2015, 101, 101-109. [CrossRef] [PubMed]

53. Islam, M.S.; Karim, M.R. Fabrication and characterization of poly (vinyl alcohol)/alginate blend nanofbers by electrospinning method. Colloids Surf. A 2010, 366, 135-140. [CrossRef]

54. Zhang, J.; Ji, Q.; Wang, F.; Tan, L.; Xia, Y. Effects of divalent metal ions on the flame retardancy and pyrolysis products of alginate fibers. Polym. Degrad. Stab. 2012, 97, 1034-1040. [CrossRef]

55. Paula, E.L.D.; Mano, V.; Pereira, F.V. Influence of cellulose nanowhiskers on the hydrolytic degradation behavior of poly (D,L-lactide). Polym. Degrad. Stab. 2011, 96, 1631-1638. [CrossRef]

56. Oleyaei, S.A.; Zahedi, Y.; Ghanbarzadeh, B.; Moayedi, A.A. Modification of physicochemical and thermal properties of starch films by incorporation of $\mathrm{TiO}_{2}$ nanoparticles. Int. J. Biol. Macromol. 2016, 89, $256-264$. [CrossRef]

57. Noshirvani, N.; Hong, W.; Ghanbarzadeh, B.; Fasihi, H.; Montazami, R. Study of cellulose nanocrystal doped starch-polyvinyl alcohol bionanocomposite films. Int. J. Biol. Macromol. 2018, 107, 2065-2074. [CrossRef]

58. Vargas, C.G.; Costa, T.M.H.; de Oliveira Rios, A.; Flôres, S.H. Comparative study on the properties of films based on red rice (Oryza glaberrima) flour and starch. Food Hydrocoll. 2017, 65, 96-106. [CrossRef]

59. Yang, L.; Paulson, A.T. Effects of lipids on mechanical and moisture barrier properties of edible gellan Film. Food Res. Int. 2000, 33, 571-578. [CrossRef]

60. Rhim, J.W. Effect of PLA lamination on performance characteristics of agar/k-Carrageenan/clay bio-nanocomposite film. Food Res. Int. 2013, 51, 714-722. [CrossRef]

61. Liang, B.; Zhao, H.; Zhang, Q.; Fan, Y.; Yue, Y.; Yin, P.; Guo, L. Ca ${ }^{2+}$ Enhanced Nacre-Inspired Montmorillonite-Alginate Film with Superior Mechanical, Transparent, Fire Retardancy, and Shape Memory Properties. ACS Sustain. Chem. Eng. 2016, 8, 28816-28823. [CrossRef]

62. Aroca, Á.S.; Iskandar, L.; Deb, S. Green synthetic routes to alginate-graphene oxide composite hydrogels with enhanced physical properties for bioengineering applications. Eur. Polym. J. 2018, 103, 198-206. [CrossRef]

63. Rhim, J.W.; Wang, L.F.; Lee, Y.; Hong, S.I. Preparation and characterization of bio-nanocomposite films of agar and silver nanoparticles: Laser ablation method. Carbohydr. Polym. 2014, 103, 456-465. [CrossRef] [PubMed]

64. Mathew, S.; Snigdha, S.; Mathew, J.; Radhakrishnan, E.K. Poly (vinyl alcohol): Montmorillonite: Boiled rice water (starch) blend film reinforced with silver nanoparticles, characterization and antibacterial properties. Appl. Clay Sci. 2018, 161, 464-473. [CrossRef]

65. Shameli, K.; Ahmad, M.B.; Yunus, W.M.Z.W.; Ibrahim, N.A.; Rahman, R.A.; Kokar, M.; Darroudi, M. Silver/poly (lactic acid) nanocomposites: Preparation, characterization, and antibacterial activity. Int. J. Nanomed. 2010, 5, 573-579. [CrossRef]

66. Bastarrachea, L.; Dhawan, S.; Sablani, S.S. Engineering properties of polymeric-based antimicrobial films for food packaging: A review. Food Eng. Rev. 2011, 3, 79-93. [CrossRef]

67. Chhatre, A.; Solasa, P.; Sakle, S.; Thaokar, R.; Mehra, A. Color and surface plasmon effects in nanoparticles systems: Case of silver nanoparticles prepared by microemulsion route. Colloid Surf. A 2012, 404, 83-92. [CrossRef] 
68. Liu, H.; Song, J.; Shang, S.; Song, Z.; Wang, D. Cellulose Nanocrystal/Silver Nanoparticle Composites as Bifunctional Nanofillers within Waterborne Polyurethane. ACS Sustain. Chem. Eng. 2012, 4, 2413-2419. [CrossRef]

69. Kumar, A.; Vemula, P.K.; Ajayan, P.M.; John, G. Silver-nanoparticle-embedded antimicrobial paints based on vegetable oil. Nat. Mater. 2008, 7, 236-241. [CrossRef]

70. Zhang, J.; Roll, D.; Geddes, C.D.; Lakowicz, J.R. Aggregation of Silver Nanoparticle-Dextran Adducts with Concanavalin A and Competitive Complexation with Glucose. J. Phys. Chem. B 2004, 108, 12210-12214. [CrossRef]

71. Hosseini, S.F.; Rezaei, M.; Zandi, M.; Farahmandghavi, F. Bio-based composite edible films containing origanum vulgare L: Essential oil. Ind. Crops Prod. 2015, 67, 403-413. [CrossRef]

72. Arfat, Y.A.; Ahmed, J.; Jacob, H. Preparation and characterization of agar-based nanocomposite films reinforced with bimetallic (Ag-Cu) alloy nanoparticles. Carbohydr. Polym. 2017, 155, 382-390. [CrossRef] [PubMed]

73. Park, C.H.; Kang, Y.K.; Im, S.S. Biodegradability of cellulose fabrics. J. Appl. Polym. Sci. 2004, 94, $248-253$. [CrossRef]

74. Yabannavar, A.; Bartha, R. Biodegradability of some food packaging materials in soil. Soil Biol. Biochem. 1993, 25, 1469-1475. [CrossRef]

(C) 2019 by the authors. Licensee MDPI, Basel, Switzerland. This article is an open access article distributed under the terms and conditions of the Creative Commons Attribution (CC BY) license (http://creativecommons.org/licenses/by/4.0/). 